\title{
Camping and quality of life
}

\author{
Frank H. Fu*, Linxuan Guo, Yanpeng Zan
}

Hong Kong Baptist University, Hong Kong, China; ${ }^{*}$ Corresponding Author: frankfu@,hkbu.edu.hk

Received 20 March 2013; revised 2 May 2013; accepted 17 May 2013

Copyright (C) 2013 Frank H. Fu et al. This is an open access article distributed under the Creative Commons Attribution License, which permits unrestricted use, distribution, and reproduction in any medium, provided the original work is properly cited.

\begin{abstract}
Attaining health and quality of life is universal among global citizens. Since its introduction by Dr. Halbert Dunn in 1962 the term wellness was used to reflect qualify of life and has been widely accepted and defined in the Western culture. In adapting this concept to the Chinese community, the components of adaptation and homeostasis should be considered in addition to physical, mental, social and health fitness. Camping is a common activity among the Western Culture which provides purposive leisure, social, education and therapeutic activities. It allows campers to escape from city life and enjoy Nature. In the Chinese community, the challenges remain to promote and develop camping to an attractive activity in the pursuit of quality of life and wellness. The present study would report the effects of selective camping programs on campers, the lifestyle management practices of Hong Kong residents and a profile of Hong Kong campers. The study was limited with data obtained from surveying 975 Hong Kong secondary school children from 11 - 18 years old using a questionnaire developed earlier [1]. Also, the case study on the effects of camping on anxiety was based on data collected from 130 campers who went to a 3-day camp.
\end{abstract}

Keywords: Lifestyle Management Practices; Outdoor Activities; Wellness

\section{EFFECTS OF CAMPING PROGRAMS}

\subsection{Quality of Life (QOL)}

Family, friends and schools are important QOL domains for adolescents with diabetes [2]. Cheung compared the quality of life (QOL) in adolescents with Type I diabetes who have attended at least one diabetes camp to those who have never attended one [3]. They found that camp attendance could provide a positive environment in which adolescents with diabetes shared knowledge of their disease with others, made friends and developed support network for one another.

Wang compared patients who did $(\mathrm{N}=77)$ and did not $(\mathrm{N}=106)$ attend a 2-day diabetes camp. They found that glycated hemoglobin Alc decreased over times in patients that attended the camp and increased in those who did not. The differences between the camper and control group remained significant after seven months. They concluded that camp attendance improved glycemic control and parent-reported adherence and adjustment in adolescents with type I diabetes [4].

Iglesias studied 548 - 14 years old children with moderate to severe asthma who attended one week camp. They concluded that the campers benefitted from the experience with a better understanding and acceptance of asthma as a chronic disease that needs medical care and treatment as well as how to better manage an attack [5]. Shepanski found that 61 patients with Crohn's and ulcerative colitis before and after a one week camp using IMPACT-II and State-Trait Anxiety questionnaires. They found that Health related QOL scores improved significantly after the camp but no significant differences in the anxiety scores [6]. O'Mahar studied 67 patients with spinal bifida after week long overnight camp. They found that campers made significant gains in individual goals, management of spinal bifida responsibilities and independence with general spinal bifida tasks [7].

\subsection{Health}

Gately studied 185 overweight children (mean age: 13.9 years) enrolled in one of four consecutive programs between 1999 and 2002 and 94 children (38 obese and 56 normal weight) of similar ages who were not campers. Each program was offered for 6 weeks in the summer. They found that campers who stayed for a mean of 29 days lost $6.0 \mathrm{~kg}$, reduced their BNMI by 2.4 units, decreased their fat mass significantly (from $42.7 \mathrm{~kg}$ to 37.1 $\mathrm{kg}$ ), significant improvements in blood pressures, aerobic fitness and self esteem. The degree of improvement was 
associated with the duration of stay. They concluded that short term weight-loss camp program was effective in improving a range of health outcomes [8].

Courey suggested that it was paramount that mental health needs of children and adolescents at camp be addressed and managed appropriately by the camp nurse [9]. Moons studied changes in the perceived health status and habitual physical activities in 25 children with congenital heart disease from attending a special three-day multi-sports camp. Significant improvements in the children's perception of their physical functioning, role-physical functioning, general health, role-emotional functioning self-esteem, mental health and general behaviour were observed. Furthermore, scores on physical functioning, role-emotional functioning, and family activities remained high three months after the camp. There was, however, no change in their habitual physical activities [10].

Wong assessed the benefits of a 2-week resident camp on 21 obese children aged $11.4 \pm 1.4$ years. They found that significant improvements in self-esteem, body weight, BMI and blood pressures and resting heart rate in the campers [11]. Snoddy and Gaslin concurred that camp environment provided an opportunity for children with hemophilia to gain independence and self-esteem [12].

Holsey and Cummings evaluated the effectiveness of an educational asthma camp program emphasizing selfmanagement skills. The campers indicated a decrease in asthma morbidity and improved asthma control after participation in the program [13]. Shelton examined the benefits of respite care for family functioning. The study focused on families of children who attended a three-day, two-night camps. It was found that parents felt that they could relax and recharge while their child was at camp and that therapeutic campus could serve respite care providers to the campers and their families [14].

\subsection{Family}

Briery suggested that family camping has an important contribution in bringing families together in the camp setting. He identified the challenges to overcome such as in the formation of cliques, sensitivity to diversity, tackling apprehensions hut concluded that with the proper themes and programs for interaction, family camping is the first step in building community - both local and global [15]. The importance of family camp in strengthening family relationships was echoed by Taylor who advocated making such camps more accessible to families [16].

Zotti found that a faith-based intervention camp for children affected by natural disaster provided countermeasures to this important public health problem [17]. Schachter advocated offering a special week-long camp for bereaved children. She witnessed significant improve- ments from the campers over a period of nine years and believed in the needs of assisting these children to overcome a highly stressful event in their life [18].

Wallace suggested that summer camp paid off in youth development. He identified benefits such as nurturing good behaviour, partnering with parent, sense of self, positive risk-taking, adult inattention and mental health as possible outcomes to assist adolescents in their lifetransitions, in becoming more proactive in participation in activities and in becoming more responsible and mature [19].

Simons examined the psychosocial changes associated with participation in a camp for 29 children with cardiac defects. They concluded that the camping environment could provide a naturalistic exposure to new experiences and successful separation from the parents and thus, promoting confidence among the parents in the ability of their children to function independently [20].

Agate and Covey categorised reasons that families attended family camps namely, therapeutic or intervention, prevention; enrichment and maintenance; and vacation. They also identified the following possible benefits from camp attendance: improving family interaction, nurturing relationships, providing social benefits and addressing specific issues [21].

The results of a Health Camp intervention for 157 children with a range of emotional and behavioral problems showed that while there were significant improvements in Strengths and Difficulties Questionnaire (in emotional, conduct, hyperactive and total problems), the parenting program had minimal impact on parenting attitudes and no adjunctive values was demonstrated [22].

Burch suggested three hypotheses in explaining leisure behaviour namely compensatory, familiarity and personal community. He believed that the latter (personal community) would be important in understanding family camps [23].

\subsection{Related Studies}

Cupers examined how throughout the first half of the 20th Century, national youth movements of different ideological stripe developed the youth camp as their central pursuit. In studying the German and United States youth camps, he found that national youth movements became concretely attracted to experiences of nature and social practices of the youth camp came to figure as practices of conduct and control [24].

Kiernan survey 2407 - 16 years old children with lifethreatening illness from 16 European countries who attended a summer therapeutic recreation program at Barretstown in Ireland in 1998. It was found that two-thirds of the participants felt that they have acquired personal and social functioning skills after the program [25].

The challenges in managing environmental impacts of 
recreation and tourism in rainforests of the wet tropics of Queensland World Heritage Areas were presented by Turton [26]. He concluded that the most appropriate management strategy for sustainable use of the WHA was to concentrate visitor activities at a small number of heavily-used sites and retention of canopy cover at camp and day use areas as well as along walking tracks and forestry roads to reduce numerous adverse impacts.

Garst studied the experiences and associated meanings of 38 US family groups participating in developed camping. They found that the key elements of camping experience included nature, social interaction, and comfort/ convenience while the most common associated meanings were restoration, family functioning, experiencing nature, special places, self-identity, social interaction, and children's learning. They concluded that meanings associated with experiencing nature, social interaction and family have evolved to reflect their greater discursive importance in contemporary society [27].

\section{LIFESTYLE MANAGEMENT}

The concept of "wellness", coined by Dr. Halbert Dunn in 1962, has affected the perception of quality of life [28]. In the Western culture, many models of wellness have been suggested but it appeared the battle against obesity was loosing ground, which led WHO to define obesity as a disease in 1998. In the Chinese community, the concept of wellness focused on harmony and homeostasis with the environment [29]. In Hong Kong where there is a good integration of the Western and Chinese culture, it appeared that a portfolio on "lifestyle management practices" might provide an alternative and more holistic benchmarking of health and quality of life.

Kang investigated the clustering of selected lifestyle factors such as cigarette smoking, heavy alcohol consumption and lack of physical exercise and identified the population characteristics associated with increasing lifestyle risks in 7694 Korean subjects. They found that in both gender, increased lifestyle risks were associated with clustering of: 1) Cigarette smoking and excessive alcohol consumption; 2) Smoking, excessive alcohol consumption and lack of physical exercise. Patterns of clustering for physical exercise was different form those for cigarette smoking and alcohol consumption. The increased unhealthy clustering was found among men 20 64 years with mild or moderate stress and among women 35 - 49 years who were never-married, with mild stress and increased BMI $\left(>30 \mathrm{~kg} / \mathrm{m}^{2}\right)[30]$.

Kosti proposed a diet-lifestyle index to be used a tool in a primary healthcare setting for preventing obesity in adolescents. Using a sample of 2008 Greek adolescents, they found the index has good relationship with changes in overweight/obesity [31]. Nowak studied 1104 Polish women aged 20 - 75 years who participated in recrea- tional activities. They identified several factors affecting their sporting lifestyle: age under 50 years, childlessness or having children over 7 years old, secondary or higher education, employment, satisfying experiences from physical activity during their childhood and youth, socio-demographic and cultural factors, and intensive sporting lifestyle promotion campaign [32].

Engstrom conducted a longitudinal study in Sweden started in 1968 on the differences in sports experiences during childhood and adolescences and differences in cultural capital on exercise habits in middle age. He found that neither memberships of a sports club nor the amount of time spent on sports activities at the age of 15 years had any significant association with the exercise habits displayed in middle age when the individual's breadth of sport experience was used as a simultaneous control but sporting breadth was significantly related to later exercise habits. He concluded that a middle-aged individual's level of exercise was closely linked to that person's social position and educational capital. Children and adolescents attaining middle-class status have higher inclination to exercise and develop strong sports habits [33].

Khaw examined the prospective relationship between lifestyle and mortality with 20,244 men and women aged 45 - 79 years with no known cardiovascular disease or cancer in the UK. They found the mortality risk was linked with four health behaviors - smoking, physically inactive, moderate alcohol intake and diet (plasma vitamin $\mathrm{C}$ and vegetable intake). Those with zero risk behavior were equivalent to be 14 years younger than those with four risk behaviors. The four health behaviors combined predicted a four-fold difference in total mortality in men and women [34]. This was supported by Mitchell who conducted a study on the health profile (cardiovascular fitness, self-reported physical activity, smoking status, alcohol consumption and body mass index) of 38,110 men and women in the US. They found that acquiring a minimum of two out of five positive health factors would reduce the risk of cardiovascular disease mortality significantly [35].

Recent research findings suggest that the lifestyle risk factors are not randomly distributed but are clustering within individuals in the general population [36]. According to a previous research on CHD risk factors cluster, drinking and smoking are identified as one cluster which is related to CHD [37]. Drinking is also identified a risk factor of obesity. Smoking and lack of physical activities will increase the prevalence of obesity. A study on elderly people analyzed the four lifestyle risk factors involving smoking cigarette, drinking alcohol, lack of physical exercise and low intake of vegetables and fruits. It was found that the prevalence of multiple risk factors was much greater among older male than older female 
[38]. Another study on lifestyles in Hong Kong was based on multiple regression analysis with age, smoking, alcohol drinking, sleeping hours and working hours. It found that BMI was independently associated with age in female, whereas waist was associated with age and smoking. In male, sleeping hours and working hours were independently associated with BMI, whereas waist was independently associated with age, smoking, sleeping hours and working hours [39].

As more and more Hong Kong children were becoming overweight with over $19 \%$ in 2008 [40]. This trend of increased prevalence was a major concern and Hong Kong children should be encouraged to exercise more and eat wisely. It was also important to help parents to be good role models for their children in fighting.

In a recent study on lifestyle management practices of 3024 randomly selected Hong Kong residents aged 5 - 74 years, $\mathrm{Fu}$ found the percentages of subjects who failed to meet some of the healthy lifestyle criteria mentioned above to be as follows: off-ranged Body Mass Index (17.5\%), off-ranged Waist Index (19.9\%), failure to meet exercise requirements (55.2\%), acquired a snack taking habit $(24.6 \%)$, acquired a habit of skipping breakfast $(13.6 \%)$, failed to eat meals regularly $(18.4 \%)$, failed to have adequate sleep $(10.2 \%)$, acquired a drinking habit (3.5\%), acquired a smoking habit $(6.8 \%)$, and habitual use of medication $(18.7 \%)$. Moreover, the study also identified the 25 - 39 years old cohort to have the worst lifestyle management practices as compared to the other three age cohorts ( $5-24,40-59$ and $60-74$ years). The findings suggested that the $25-39$ years cohort led a more unhealthy lifestyle in comparison with other age cohorts - they exercised less, had more breakfast skipping and irregular meals, slept less and smoked more. It was also found that the health status of the blue collar (labour) workers was worse than the white collar counterpart. The poor health awareness among the blue collar workers might be a possible explanation for this phenomenon. With regard to the habits of sleeping and eating, it was found that $20 \%$ of the subjects surveyed slept less than six hours per day and $20 \%$ of them did not eat their three meals regularly. Four clusters of health related lifestyle items were also identified by the Ward's method:

1) Body mass Index (BMI), waist index (WI), drinking, smoking, exercise expenditure and medical expenditure;

2) Exercise frequency, snacks and sleeping hours;

3) Breakfast and regular meals; and

4) Usage of medication.

The norms for designing the ratings of the various parameters in the questionnaire are adopted from an early study (Fu et al., 2011) and are as followed:

Overweight and obesity (BMI > 25) (Lenz, Richter, \& Mühlhauser, 2009);
Abdominal obesity (WI > 0.5) (Browning et al., 2010);

Sedentary working pattern (van Uffelen et al., 2010);

Exercise frequency ( $\leq 1 /$ week) (ACSM, 2009);

Snacks taking ( $\geq 4$ - 6/week, breakfast taking $\leq 3 /$ week, regular meals $\leq 3 /$ week) (McCrory \& Campbell, 2011);

Sleeping hours ( $\leq 6 \mathrm{~h} /$ day) (Knutson, 2010);

Drinking ( $\geq 3 /$ week);

Smoking ( $\geq 3 /$ week);

Medication usage ( $\geq 3$ week), and

Exercise expenditure $(\leq \mathrm{HK} \$ 1000$ or medical expenditure $\geq$ HK \$1000).

It appeared that city dwellers in developing countries were affected by other lifestyle practices than the nature of the job alone. It was suggested that Hong Kong residents should reduce their usage of medication and exercise more as well as further reduce the habit of drinking and smoking. It was recommended that interventions for various age cohorts should be designed and implemented in light of the findings in the future [1].

\section{PROFILE OF HONG KONG SCHOOL STUDENTS}

The literature indicated that camping might be a useful tool in the education and changing the attitudes and lifestyle habits of the campers. In order to make camping more effective, it is important to better understand the profile of the students such as in lifestyle management practices, attitude towards and expectations from camping .The present project conducted a survey of 975 Hong Kong secondary students. The results are presented in the following paragraphs (Tables 1-9).

From the investigation, it was found that $15.7 \%$ of students surveyed had no camping experiences. It was also found that they participated in camps of relatively short duration such as 3 - 5 days (Table 10).

The findings of the project also suggested that camping has no effects on the General self-efficacy (GES) and Rosenberg Self-Esteem (RSE) of the participants (Table 11).

\section{A Case Study}

The effects of a 3 days camp at Wu Kai Sha, Hong Kong were investigated. It was found that participants' level of anxiety decreased significantly (Table 12).

\section{SUMMARY}

Overseas experience suggested that camping is a meaningful outdoor activity that can provide educational, recreational, therapeutic, social, and family bonding opportunities [2-26]. A recent study on lifestyle survey of Hong Kong residents indicated that our work force, especially the manual workers and the age cohort of 25 - 
Table 1. Demographic characteristics of subjects.

\begin{tabular}{|c|c|c|c|c|}
\hline Age group & Male & \multicolumn{2}{|c|}{ Female } & Total \\
\hline 11 & 9 & \multicolumn{2}{|r|}{15} & 24 \\
\hline 12 & 105 & \multicolumn{2}{|r|}{76} & 181 \\
\hline 13 & 66 & \multicolumn{2}{|r|}{66} & 132 \\
\hline 14 & 145 & \multicolumn{2}{|r|}{63} & 208 \\
\hline 15 & 90 & \multicolumn{2}{|r|}{85} & 175 \\
\hline 16 & 80 & \multicolumn{2}{|r|}{65} & 145 \\
\hline 17 & 56 & \multicolumn{2}{|r|}{40} & 96 \\
\hline 18 & 5 & \multicolumn{2}{|r|}{9} & 14 \\
\hline Total & 556 & \multicolumn{2}{|r|}{419} & 975 \\
\hline \multicolumn{5}{|c|}{ Chi-Square Measure } \\
\hline & Value & $\mathrm{df}$ & $\begin{array}{l}\text { Asymp. Sig. } \\
\text { (2-sided) }\end{array}$ & $\begin{array}{c}\text { Point } \\
\text { Probability }\end{array}$ \\
\hline Pearson Chi-Square & $25.225^{\mathrm{a}}$ & 7 & \multicolumn{2}{|l|}{0.001} \\
\hline Likelihood Ratio & 25.625 & 7 & \multicolumn{2}{|l|}{0.001} \\
\hline $\begin{array}{l}\text { Linear-by-Linear } \\
\text { Association }\end{array}$ & $0.018^{\mathrm{c}}$ & 1 & \multirow[t]{2}{*}{0.893} & \multirow[t]{2}{*}{0.015} \\
\hline $\mathrm{N}$ of Valid Cases & 975 & & & \\
\hline \multicolumn{5}{|c|}{ Symmetric Measures } \\
\hline & Value & Approx. Sig. & Exact Sig. \\
\hline \multirow{2}{*}{$\begin{array}{l}\text { Nominal by } \\
\text { Nominal }\end{array}$} & Phi & 0.161 & 0.001 & $\mathrm{a}^{\mathrm{a}}$ \\
\hline & Cramer's V & 0.161 & 0.001 &.$^{\mathrm{a}}$ \\
\hline \multicolumn{2}{|c|}{$\mathrm{N}$ of Valid Cases } & 975 & & \\
\hline
\end{tabular}

${ }^{a}$ Cannot be computed because there is insufficient memory.

Table 2. BMI and waist of subjects.

\begin{tabular}{ccccc}
\hline \multirow{2}{*}{$\begin{array}{c}\text { Age } \\
\text { group }\end{array}$} & \multicolumn{2}{c}{ BMI $\left(\mathrm{kg} / \mathrm{m}^{2}\right)$} & \multicolumn{2}{c}{ Wais } \\
& $(\mathrm{n}=487)$ & $\begin{array}{c}\text { Female } \\
(\mathrm{n}=368)\end{array}$ & $\begin{array}{c}\text { Male } \\
(\mathrm{n}=376)\end{array}$ & $\begin{array}{c}\text { Female } \\
(\mathrm{n}=264)\end{array}$ \\
\hline 11 & $16.8 \pm 2.7$ & $17.7 \pm 2.5$ & $64.6 \pm 9.9$ & $63.5 \pm 14.5$ \\
12 & $18.4 \pm 3.1$ & $18.0 \pm 3.6$ & $69.7 \pm 10.9$ & $65.8 \pm 9.7$ \\
13 & $18.9 \pm 2.6$ & $18.8 \pm 3.6$ & $70.3 \pm 8.6$ & $65.4 \pm 8.7$ \\
14 & $19.2 \pm 3.9$ & $19.5 \pm 4.0$ & $70.2 \pm 11.8$ & $62.4 \pm 8.9$ \\
15 & $20.2 \pm 3.3$ & $19.6 \pm 2.3$ & $72.9 \pm 10.3$ & $64.1 \pm 10.1$ \\
16 & $20.6 \pm 3.0$ & $20.1 \pm 2.1$ & $72.2 \pm 8.6$ & $67.0 \pm 8.1$ \\
17 & $20.7 \pm 4.2$ & $20.1 \pm 2.7$ & $73.2 \pm 12.0$ & $67.7 \pm 10.0$ \\
18 & $19.7 \pm 1.6$ & $18.8 \pm 4.9$ & $76.2 \pm 7.2$ & $65.4 \pm 4.0$ \\
$11-18$ & $19.5 \pm 3.5$ & $19.1 \pm 3.2$ & $71.0 \pm 10.6$ & $65.2 \pm 9.6$ \\
\hline
\end{tabular}

BMI: $\mathrm{F}=7.701, \mathrm{p}<0.01$, Partial $\eta^{2}=0.06 ;$ Age 11/15 - 17, Age 12/15 - 17, Age 13/16 - 17 Waist: $\mathrm{F}=25.154, \mathrm{p}<0.01$, Partial $\eta^{2}=0.39$; between Gen$\operatorname{der} \mathrm{F}=1.777, \mathrm{p}=0.089$, Partial $\eta^{2}=0.20$; None of age group.
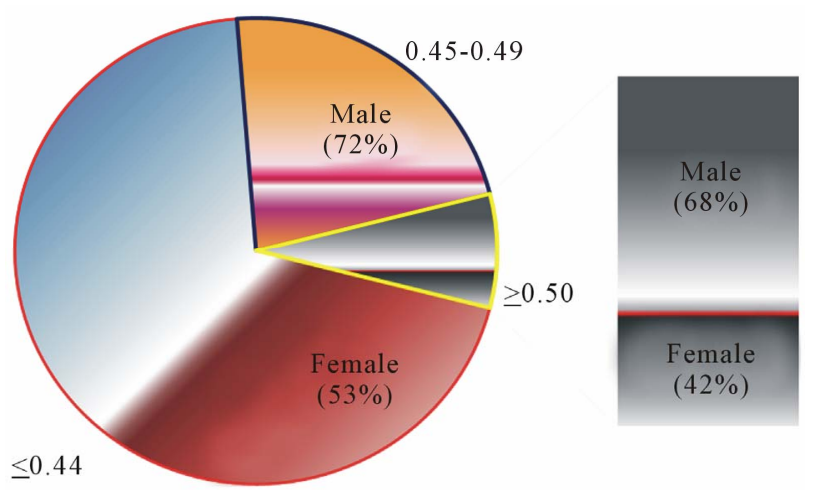

Table 3. (a) Participation of physical activity weekly; (b) Motivation for regular physical activity.

\begin{tabular}{|c|c|c|c|c|c|c|c|c|}
\hline & & & Never & $\begin{array}{c}1-2 \\
\text { times }\end{array}$ & $\begin{array}{c}3-4 \\
\text { times }\end{array}$ & $\begin{array}{c}5-6 \\
\text { times }\end{array}$ & $\begin{array}{c}\text { Every } \\
\text { day }\end{array}$ & Total \\
\hline \multirow{6}{*}{ Gender } & \multirow{2}{*}{ Lost } & Count & 0 & 7 & 2 & 1 & 4 & 14 \\
\hline & & $\%$ of Total & $0.0 \%$ & $0.7 \%$ & $0.2 \%$ & $0.1 \%$ & $0.4 \%$ & $1.5 \%$ \\
\hline & \multirow{2}{*}{ Male } & Count & 13 & 210 & 147 & 128 & 43 & 541 \\
\hline & & $\%$ of Total & $1.4 \%$ & $22.1 \%$ & $15.4 \%$ & $13.4 \%$ & $4.5 \%$ & $56.8 \%$ \\
\hline & \multirow{2}{*}{ Female } & Count & 8 & 193 & 109 & 68 & 19 & 397 \\
\hline & & $\%$ of Total & $.8 \%$ & $20.3 \%$ & $11.4 \%$ & $7.1 \%$ & $2.0 \%$ & $41.7 \%$ \\
\hline \multirow{2}{*}{\multicolumn{2}{|c|}{ Total }} & Count & 21 & 410 & 258 & 197 & 66 & 952 \\
\hline & & $\%$ of Total & $2.2 \%$ & $43.1 \%$ & $27.1 \%$ & $20.7 \%$ & $6.9 \%$ & $100.0 \%$ \\
\hline
\end{tabular}

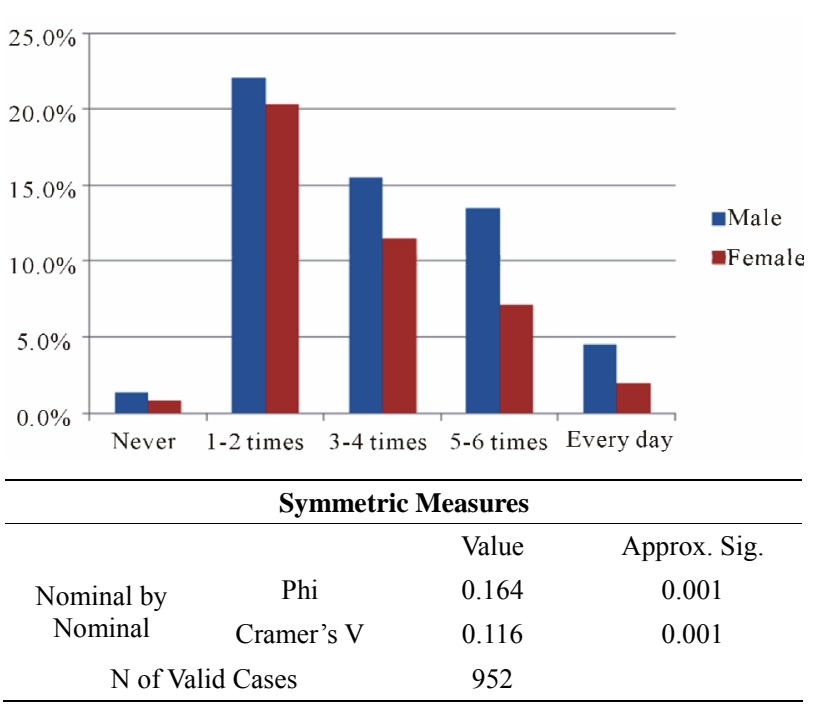

\begin{tabular}{|c|c|c|c|c|c|c|}
\hline & & & $\begin{array}{l}\text { Never } \\
\text { thought }\end{array}$ & $\begin{array}{l}\text { Have } \\
\text { thought }\end{array}$ & $\begin{array}{c}\text { Have } \\
\text { made plans }\end{array}$ & Total \\
\hline \multirow{6}{*}{ Gender } & \multirow{2}{*}{ Lost } & Count & 1 & 2 & 8 & 11 \\
\hline & & $\%$ of Total & $0.2 \%$ & $0.4 \%$ & $1.5 \%$ & $2.1 \%$ \\
\hline & \multirow{2}{*}{ Male } & Count & 21 & 102 & 148 & 271 \\
\hline & & $\%$ of Total & $4.0 \%$ & $19.4 \%$ & $28.1 \%$ & $51.4 \%$ \\
\hline & \multirow{2}{*}{ Female } & Count & 16 & 80 & 149 & 245 \\
\hline & & $\%$ of Total & $3.0 \%$ & $15.2 \%$ & $28.3 \%$ & $46.5 \%$ \\
\hline \multirow{2}{*}{\multicolumn{2}{|c|}{ Total }} & Count & 38 & 184 & 305 & 527 \\
\hline & & $\%$ of Total & $7.2 \%$ & $34.9 \%$ & $57.9 \%$ & $100.0 \%$ \\
\hline
\end{tabular}

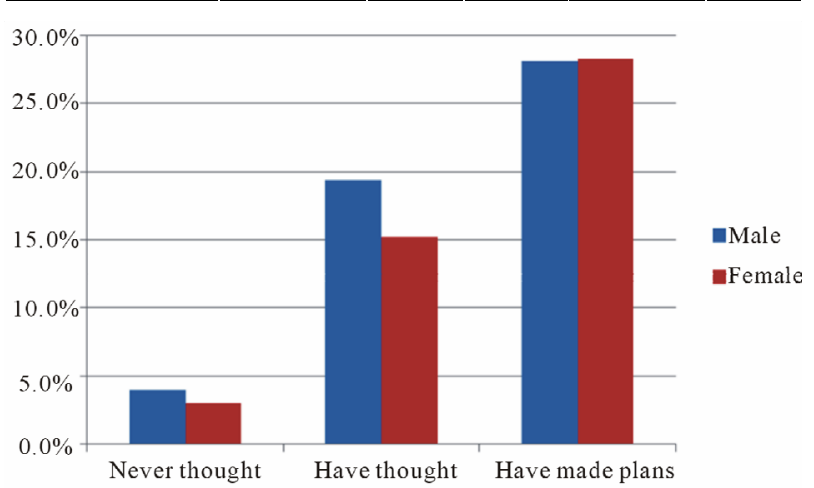


Table 4. (a) Snacks taking habit; (b) Decreasing Snacks taking. (a)

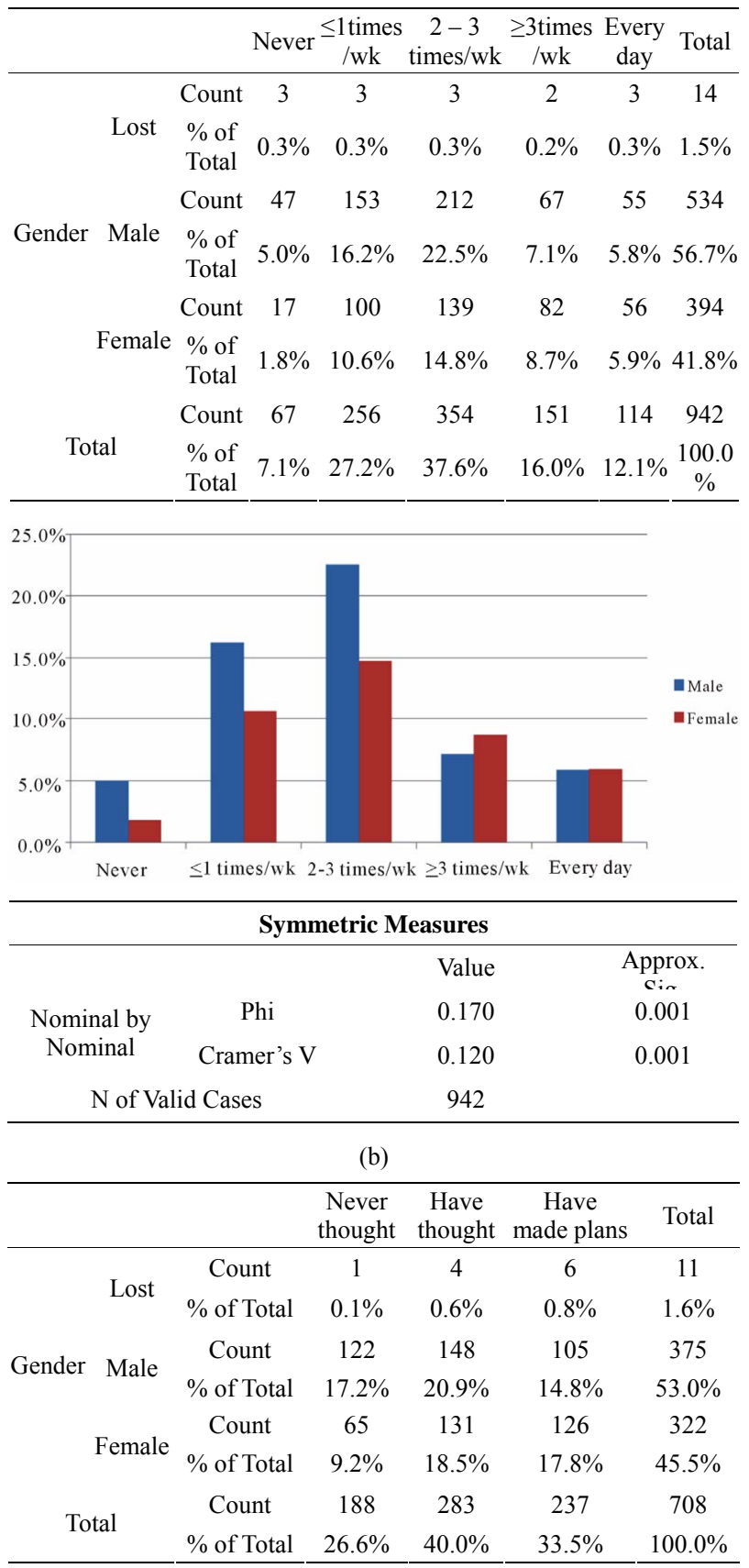

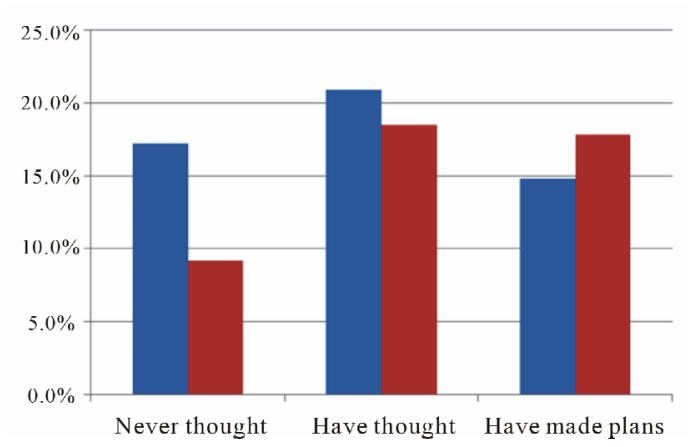

Male -Female

\begin{tabular}{cccc}
\hline \multicolumn{4}{c}{ Symmetric Measures } \\
\hline & & Value & Approx. Sig. \\
Nominal by & Phi & 0.165 & 0.001 \\
Nominal & Cramer's V & 0.117 & 0.001 \\
N of Valid Cases & 708 & \\
\hline
\end{tabular}

Table 5. (a) Breakfast habit; (b) Regular breakfast eating.

(a)

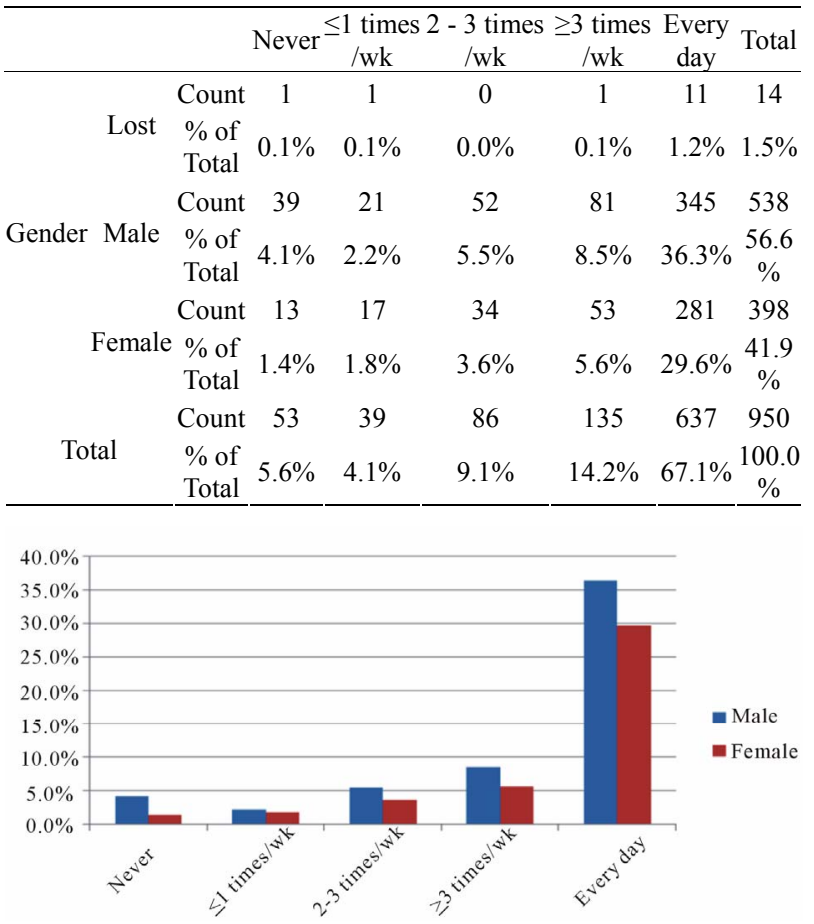

(b)

\begin{tabular}{|c|c|c|c|c|c|c|}
\hline & & & $\begin{array}{c}\text { Never } \\
\text { thought }\end{array}$ & $\begin{array}{c}\text { Have } \\
\text { thought }\end{array}$ & $\begin{array}{c}\text { Have } \\
\text { made plans }\end{array}$ & Total \\
\hline \multirow{6}{*}{ Gender } & \multirow{2}{*}{ Lost } & Count & 1 & 0 & 5 & 6 \\
\hline & & $\%$ of Total & $0.3 \%$ & $0.0 \%$ & $1.6 \%$ & $1.9 \%$ \\
\hline & \multirow{2}{*}{ Male } & Count & 45 & 54 & 82 & 181 \\
\hline & & $\%$ of Total & $14.2 \%$ & $17.0 \%$ & $25.8 \%$ & $56.9 \%$ \\
\hline & \multirow{2}{*}{ Female } & Count & 34 & 33 & 64 & 131 \\
\hline & & $\%$ of Total & $10.7 \%$ & $10.4 \%$ & $20.1 \%$ & $41.2 \%$ \\
\hline \multirow{2}{*}{\multicolumn{2}{|c|}{ Total }} & Count & 80 & 87 & 151 & 318 \\
\hline & & $\%$ of Total & $25.2 \%$ & $27.4 \%$ & $47.5 \%$ & $100.0 \%$ \\
\hline
\end{tabular}

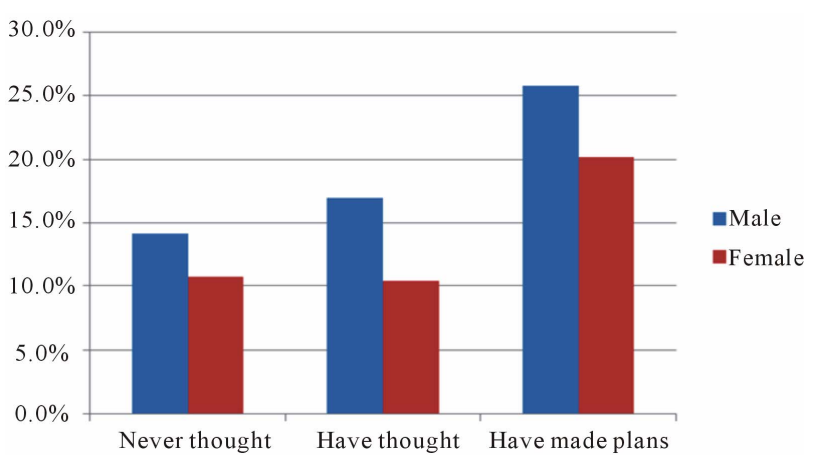


Table 6. (a) Eating regular meals; (b) Sleeping hours.

(a)

\begin{tabular}{|c|c|c|c|c|c|c|c|c|}
\hline & & & Never & $\begin{array}{c}\leq 1 \\
\text { imes/wk }\end{array}$ & $\begin{array}{c}2-3 \\
\text { times/wk }\end{array}$ & $\begin{array}{c}\geq 3 \\
\text { times/wk }\end{array}$ & $\begin{array}{l}\text { Every } \\
\text { K day }\end{array}$ & Total \\
\hline \multirow{6}{*}{ Gender } & \multirow[b]{2}{*}{ Lost } & Count & 1 & 1 & 0 & 3 & 9 & 14 \\
\hline & & $\begin{array}{l}\% \text { of } \\
\text { Total }\end{array}$ & $0.1 \%$ & $0.1 \%$ & $0.0 \%$ & $0.3 \%$ & $1.0 \%$ & $1.5 \%$ \\
\hline & \multirow[b]{2}{*}{ Male } & Count & t 30 & 28 & 77 & 103 & 296 & 534 \\
\hline & & $\begin{array}{l}\% \text { of } \\
\text { Total }\end{array}$ & $3.2 \%$ & $3.0 \%$ & $8.2 \%$ & $10.9 \%$ & $\begin{array}{c}31.4 \\
\%\end{array}$ & $\begin{array}{c}56.7 \\
\%\end{array}$ \\
\hline & \multirow[b]{2}{*}{ Female } & Count & 21 & 19 & 54 & 83 & 217 & 394 \\
\hline & & $\begin{array}{l}\% \text { of } \\
\text { Total }\end{array}$ & $2.2 \%$ & $2.0 \%$ & $5.7 \%$ & $8.8 \%$ & $\begin{array}{c}23.0 \\
\%\end{array}$ & $\begin{array}{c}41.8 \\
\%\end{array}$ \\
\hline \multirow{2}{*}{\multicolumn{2}{|c|}{ Total }} & Count & 52 & 48 & 131 & 189 & 522 & 942 \\
\hline & & $\begin{array}{l}\% \text { of } \\
\text { Total }\end{array}$ & $5.5 \%$ & $5.1 \%$ & $13.9 \%$ & $20.1 \%$ & $\begin{array}{c}55.4 \\
\%\end{array}$ & $\begin{array}{c}100.0 \\
\%\end{array}$ \\
\hline
\end{tabular}

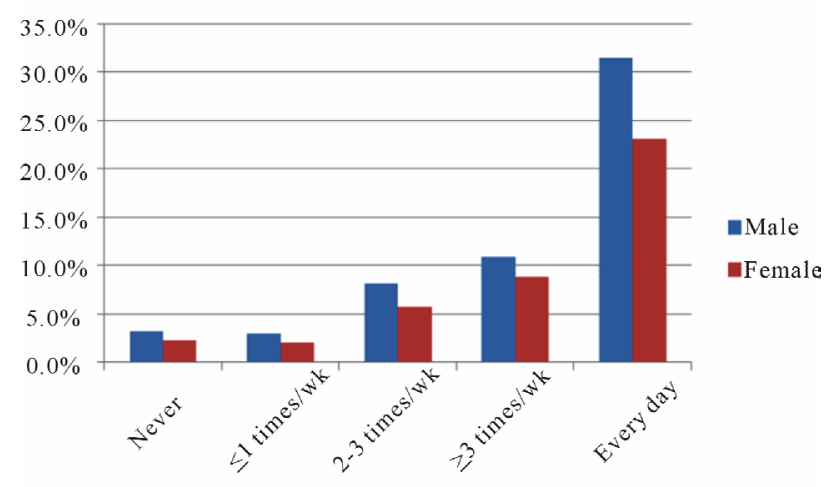

(b)

\begin{tabular}{ccccccc}
\hline \multirow{4}{*}{ Lost } & & $\begin{array}{c}\text { Never } \\
\text { thought }\end{array}$ & $\begin{array}{c}\text { Have } \\
\text { thought }\end{array}$ & $\begin{array}{c}\text { Have made } \\
\text { plans }\end{array}$ & Total \\
\hline \multirow{4}{*}{ Gender } & Count & 2 & 1 & 5 & 8 \\
& & Male of Total & $0.6 \%$ & $0.3 \%$ & $1.5 \%$ & $2.4 \%$ \\
& & Count & 46 & 61 & 76 & 183 \\
& & \% of Total & $13.8 \%$ & $18.3 \%$ & $22.8 \%$ & $54.8 \%$ \\
\multirow{2}{*}{ Female } & Count & 39 & 47 & 57 & 143 \\
& & \% of Total & $11.7 \%$ & $14.1 \%$ & $17.1 \%$ & $42.8 \%$ \\
\multirow{2}{*}{ Total } & Count & 87 & 109 & 138 & 334 \\
& \% of Total & $26.0 \%$ & $32.6 \%$ & $41.3 \%$ & $100.0 \%$ \\
\hline
\end{tabular}

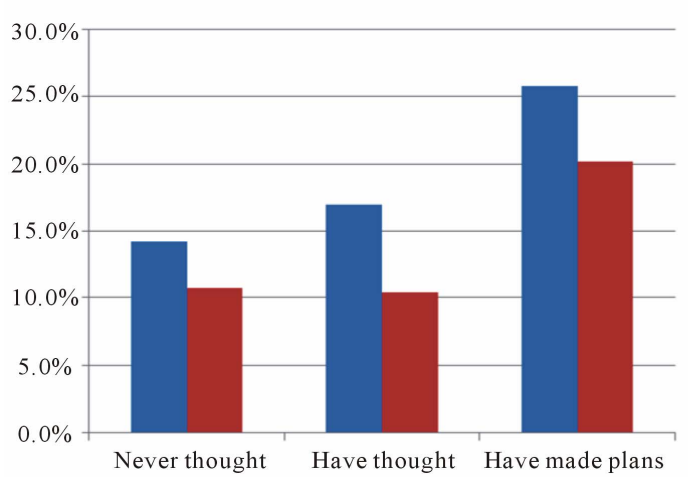

Male

-Female
Table 7. (a) Sleeping hours; (b) Increase of sleeping hours.

\begin{tabular}{|c|c|c|c|c|c|c|}
\hline & & & $\begin{array}{l}\text { Never } \\
\text { thought }\end{array}$ & $\begin{array}{c}\text { Have } \\
\text { thought }\end{array}$ & $\begin{array}{l}\text { Have made } \\
\text { plans }\end{array}$ & Total \\
\hline \multirow{6}{*}{ Gender } & \multirow{2}{*}{ Lost } & Count & 1 & 0 & 5 & 6 \\
\hline & & $\%$ of Total & $0.3 \%$ & $0.0 \%$ & $1.6 \%$ & $1.9 \%$ \\
\hline & \multirow{2}{*}{ Male } & Count & 45 & 54 & 82 & 181 \\
\hline & & $\%$ of Total & $14.2 \%$ & $17.0 \%$ & $25.8 \%$ & $56.9 \%$ \\
\hline & \multirow{2}{*}{ Female } & Count & 34 & 33 & 64 & 131 \\
\hline & & $\%$ of Total & $10.7 \%$ & $10.4 \%$ & $20.1 \%$ & $41.2 \%$ \\
\hline \multirow{2}{*}{\multicolumn{2}{|c|}{ Total }} & Count & 80 & 87 & 151 & 318 \\
\hline & & $\%$ of Total & $25.2 \%$ & $27.4 \%$ & $47.5 \%$ & $100.0 \%$ \\
\hline
\end{tabular}

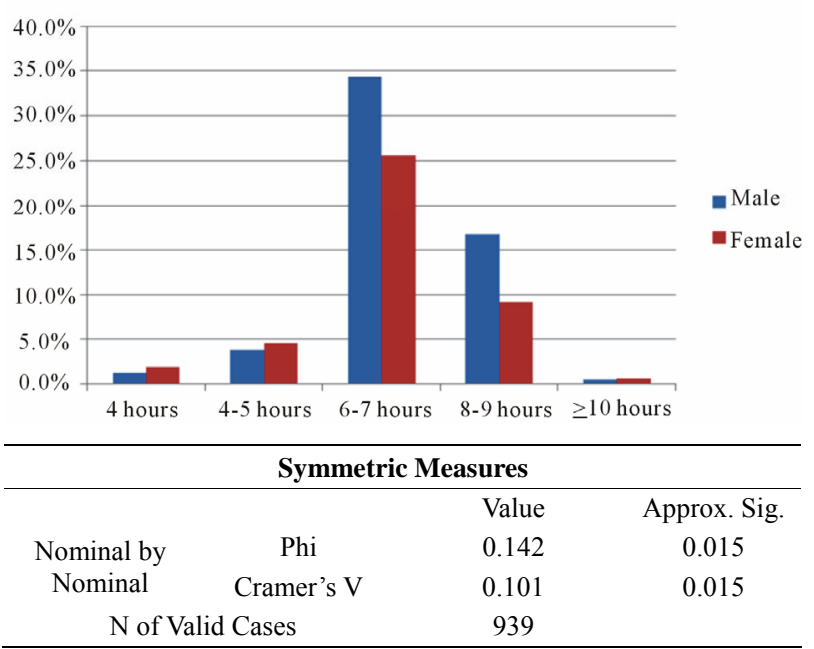

(b)

\begin{tabular}{|c|c|c|c|c|c|c|}
\hline & & & $\begin{array}{c}\text { Never } \\
\text { thought }\end{array}$ & $\begin{array}{c}\text { Have } \\
\text { thought }\end{array}$ & $\begin{array}{l}\text { Have made } \\
\text { plans }\end{array}$ & Total \\
\hline \multirow{6}{*}{ Gender } & \multirow{2}{*}{ Lost } & Count & 1 & 0 & 5 & 6 \\
\hline & & $\%$ of Total & $0.3 \%$ & $0.0 \%$ & $1.6 \%$ & $1.9 \%$ \\
\hline & \multirow{2}{*}{ Male } & Count & 45 & 54 & 82 & 181 \\
\hline & & $\%$ of Total & $14.2 \%$ & $17.0 \%$ & $25.8 \%$ & $56.9 \%$ \\
\hline & \multirow{2}{*}{ Female } & Count & 34 & 33 & 64 & 131 \\
\hline & & $\%$ of Total & $10.7 \%$ & $10.4 \%$ & $20.1 \%$ & $41.2 \%$ \\
\hline \multirow{2}{*}{\multicolumn{2}{|c|}{ Total }} & Count & 80 & 87 & 151 & 318 \\
\hline & & $\%$ of Total & $25.2 \%$ & $27.4 \%$ & $47.5 \%$ & $100.0 \%$ \\
\hline
\end{tabular}

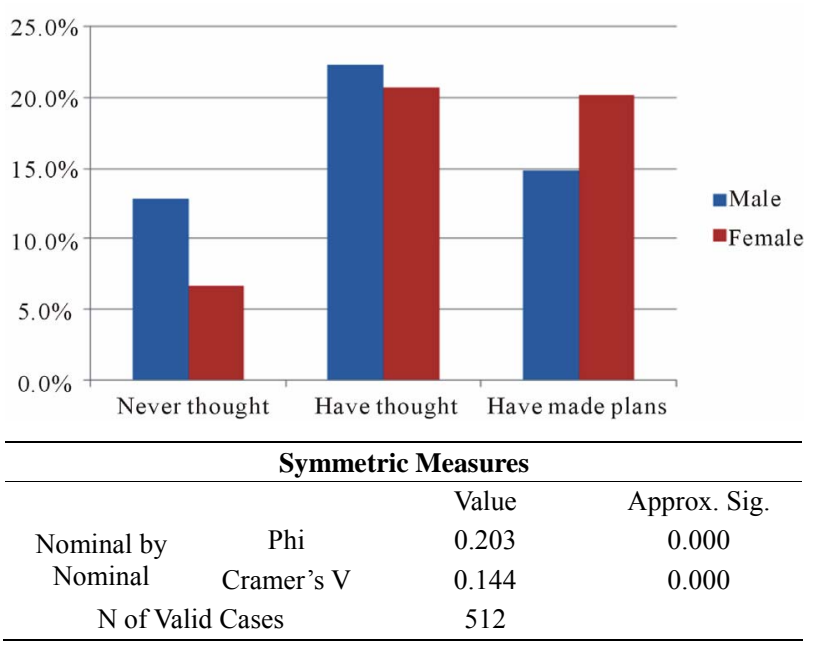


Table 8. (a) Participation of camping; (b) Increase participation of camping.

(a)

\begin{tabular}{|c|c|c|c|c|c|c|c|c|}
\hline & & & Never & $\begin{array}{l}\leq 1 \\
\text { times/yr }\end{array}$ & $\begin{array}{c}2-3 \\
\text { times/yr }\end{array}$ & $\begin{array}{l}\geq 3 \\
\text { times/yr }\end{array}$ & $\begin{array}{l}\text { Every } \\
\text { month }\end{array}$ & Total \\
\hline \multirow{6}{*}{ Gender } & \multirow[b]{2}{*}{ Lost } & Count & 2 & 6 & 3 & 3 & 0 & 14 \\
\hline & & $\begin{array}{l}\% \text { of } \\
\text { Total }\end{array}$ & $0.2 \%$ & $0.6 \%$ & $0.3 \%$ & $0.3 \%$ & $0.0 \%$ & $1.5 \%$ \\
\hline & \multirow[b]{2}{*}{ Male } & Count & 91 & 238 & 157 & 43 & 3 & 532 \\
\hline & & $\begin{array}{l}\% \text { of } \\
\text { Total }\end{array}$ & $9.7 \%$ & $25.4 \%$ & $16.8 \%$ & $4.6 \%$ & $0.3 \%$ & $\begin{array}{c}56.8 \\
\%\end{array}$ \\
\hline & \multirow{2}{*}{ Femal } & Count & 54 & 175 & 130 & 30 & 2 & 391 \\
\hline & & $\begin{array}{l}\% \text { of } \\
\text { Total }\end{array}$ & $5.8 \%$ & $18.7 \%$ & $13.9 \%$ & $3.2 \%$ & $.2 \%$ & $\begin{array}{c}41.7 \\
\%\end{array}$ \\
\hline \multirow{2}{*}{\multicolumn{2}{|c|}{ Total }} & Count & 147 & 419 & 290 & 76 & 5 & 937 \\
\hline & & $\begin{array}{l}\% \text { of } \\
\text { Total }\end{array}$ & $\begin{array}{c}15.7 \\
\%\end{array}$ & $44.7 \%$ & $30.9 \%$ & $8.1 \%$ & $.5 \%$ & $\begin{array}{c}100 . \\
0 \%\end{array}$ \\
\hline
\end{tabular}

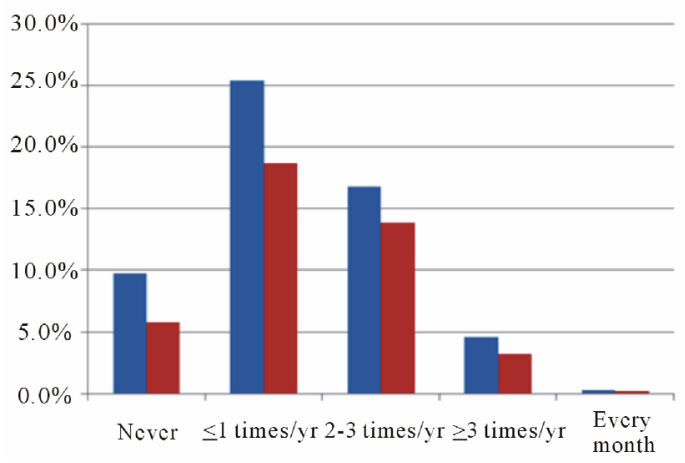

(b)

\begin{tabular}{ccccccc}
\hline & & $\begin{array}{c}\text { Never } \\
\text { thought }\end{array}$ & $\begin{array}{c}\text { Have } \\
\text { thought }\end{array}$ & $\begin{array}{c}\text { Have made } \\
\text { plans }\end{array}$ & Total \\
\hline \multirow{4}{*}{ Lost } & Count & 4 & 5 & 3 & 12 \\
& & \% of Total & $0.6 \%$ & $0.7 \%$ & $0.4 \%$ & $1.8 \%$ \\
\multirow{3}{*}{ Gender } & Male & Count & 172 & 143 & 55 & 370 \\
& & \% of Total & $25.1 \%$ & $20.9 \%$ & $8.0 \%$ & $54.1 \%$ \\
\multirow{2}{*}{ Female } & Count & 116 & 135 & 51 & 302 \\
& & \% of Total & $17.0 \%$ & $19.7 \%$ & $7.5 \%$ & $44.2 \%$ \\
\multirow{2}{*}{ Total } & Count & 292 & 283 & 109 & 684 \\
& \% of Total & $42.7 \%$ & $41.4 \%$ & $15.9 \%$ & $100.0 \%$ \\
\hline
\end{tabular}

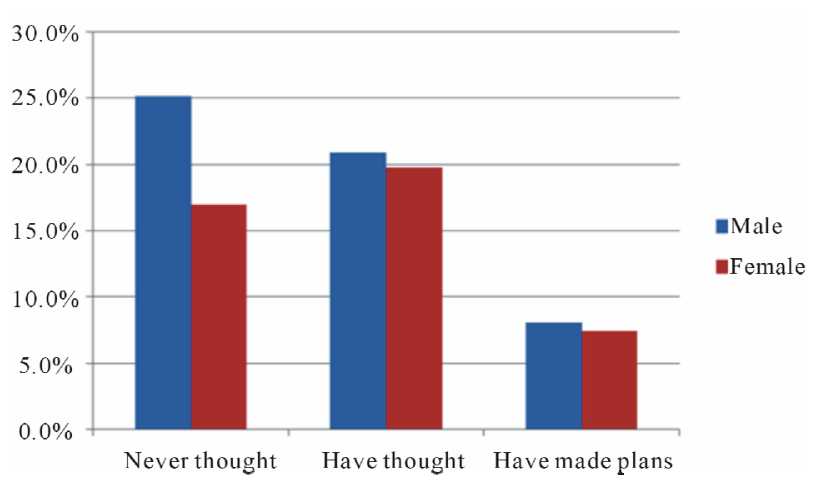

Table 9. Desired duration of camping.

\begin{tabular}{|c|c|c|c|c|c|c|}
\hline & & & 1 - 3 days & 4 - 7 days & $>7$ days & Total \\
\hline \multirow{6}{*}{ Gender } & \multirow{2}{*}{ Lost } & Count & 0 & 3 & 2 & 5 \\
\hline & & $\%$ of Total & $0.0 \%$ & $0.5 \%$ & $0.3 \%$ & $0.9 \%$ \\
\hline & \multirow{2}{*}{ Male } & Count & 188 & 114 & 43 & 345 \\
\hline & & $\%$ of Total & $32.5 \%$ & $19.7 \%$ & $7.4 \%$ & $59.7 \%$ \\
\hline & \multirow{2}{*}{ Female } & Count & 137 & 76 & 15 & 228 \\
\hline & & $\%$ of Total & $23.7 \%$ & $13.1 \%$ & $2.6 \%$ & $39.4 \%$ \\
\hline \multirow{2}{*}{\multicolumn{2}{|c|}{ Total }} & Count & 325 & 193 & 60 & 578 \\
\hline & & $\%$ of Total & $56.2 \%$ & $33.4 \%$ & $10.4 \%$ & $100.0 \%$ \\
\hline
\end{tabular}

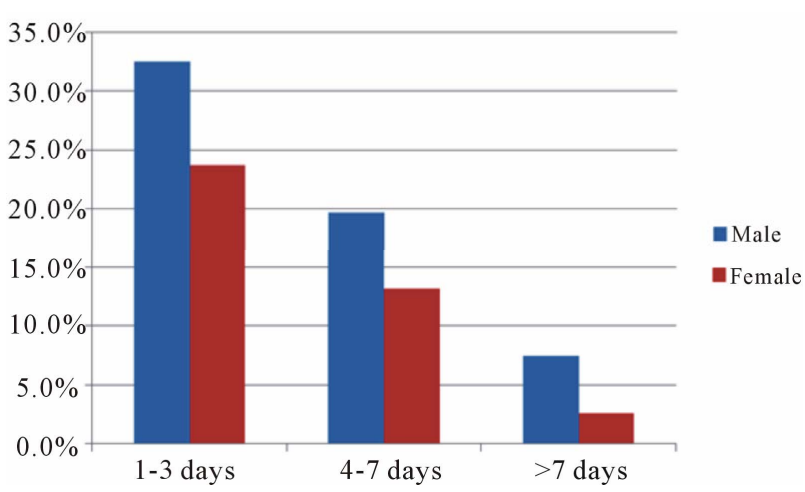

Table 10. Effects of camping on GES and RSE.

\begin{tabular}{ccccc}
\hline & & Score & $\mathrm{t}$ & $\mathrm{p}$ \\
\hline \multirow{2}{*}{ GES } & No participation (103) & $27.9 \pm 5.9$ & & \\
& Have participation (489) & $28.7 \pm 4.7$ & -1.53 & 0.13 \\
\multirow{2}{*}{ RSE } & No participation (103) & $17.9 \pm 4.7$ & & \\
& Have participation (490) & $18.7 \pm 4.7$ & -1.47 & 0.14 \\
\hline
\end{tabular}

Table 11. Effects of camping frequency on GES and RSE.

\begin{tabular}{cccc}
\hline & GES & RSE \\
\hline No participation $(\mathrm{n}=103)$ & $27.9 \pm 5.9$ & $17.9 \pm 4.7$ \\
$\leq 1$ times/year $(\mathrm{n}=287)$ & $28.4 \pm 4.5$ & $\mathrm{~F}=1.80$ & $18.6 \pm 4.6 \quad \mathrm{~F}=1.56$ \\
2 times/year $(\mathrm{n}=164)$ & $29.0 \pm 4.6$ & $\mathrm{P}=0.13$ & $19.1 \pm 4.9 \quad \mathrm{P}=0.19$ \\
$\geq 3$ times/year $(\mathrm{n}=38)$ & $30.0 \pm 5.9$ & $17.6 \pm 4.9$ \\
\hline
\end{tabular}

Table 12. Results of paired t-tests for State Anxiety Inventory (SAI) and Trait Anxiety Inventory (TAI).

\begin{tabular}{cccccc}
\hline & & Score & T & df & P \\
\hline \multirow{2}{*}{ SAI } & Pre & $45.2 \pm 8.1$ & 5.24 & 129 & 0.000 \\
& Post & $35.9 \pm 19.9$ & & & \\
\multirow{2}{*}{ TAI } & Pre & $45.5 \pm 8.1$ & 5.87 & 129 & 0.000 \\
& Post & $35.3 \pm 19.6$ & & & \\
\hline
\end{tabular}

39 years, led the worst lifestyle. There is a dire need to provide opportunities to modify lifestyle for this age cohort and camping is an excellent option. While camping 
is a new leisure activity for the Chinese community, its benefits are widely reported in studies in the Western society [2-26]. Recent research findings suggested that there is an urgent need to improve the lifestyle management practices of the general public [1,27-38]. With the air quality of in urban area below average (Air Pollution Index $>50$ ) for over $70 \%$ of the year, it would be highly desirable for Hong Kong residents to enjoy better air quality in rural and outdoor venues through camping. It is believed that the promotion and developing of camping in Hong Kong is important and will enhance the quality of life of the residents. However, this would require long term vision and support of the SAR Government as well as NGOs. Together, we can contribute to improving the quality of life and developing better lifestyle for our Hong Kong residents in the years ahead.

\section{REFERENCES}

[1] Fu, F.H., An, N. and Li. G.Z. (2011) Lifestyle management practices of Hong Kong people. Hong Kong Baptist University.

[2] Walker, J. and Bradley, C. (2002) Assessing the quality of life of adolescents with diabetes: Using the SEIQoL, DQoL, patient and diabetes specialist nurse ratings. Practical Diabetes International, 19, 141-144. doi:10.1002/pdi.348

[3] Cheung, R., Young, Cureton, V. and Canham, D.L. (2006) Quality of life in adolescents with type 1 diabetes who participate in diabetes camp. The Journal of School Nursing, 22, 53-58. doi:10.1177/10598405060220010901

[4] Wang, Y.C., Stewart, S., Tuli, E. and White, P. (2008) Improved glycemic control in adolescents with type 1 diabetes mellitus who attend diabetes camp. Pediatric Diabetes, 9, 29-34. doi:10.1111/j.1399-5448.2007.00285.x

[5] Iglesias, M.A., Díaz Jara, M., Zapatero Remón, L. and Martínez Molero, M.I. (2003) Asthma camp. Quality of life questionnaires. Allergologia et Immunopathologia (Madrid), 31, 231-235.

[6] Shepanski, M.A., Hurd, L.B., Culton, K., Markowitz, J.E., Mamula, P. and Baldassano, R.N. (2005) Health-related quality of life improves in children and adolescents with inflammatory bowel disease after attending a camp sponsored by the Crohn's and Colitis Foundation of America. Inflammatory Bowel Disease, 11, 164-170. doi:10.1097/00054725-200502000-00010

[7] O'Mahar, K., Holmbeck, G.N., Jandasek, B. and Zukerman, J. (2010) A camp-based intervention targeting independence among individuals with spinal bifida. Journal of Pediatric Psychology, 35, 848-856. doi:10.1093/jpepsy/jsp125

[8] Gately, P.J., Cooke, C.B., Barth, J.H., Bewick, B.M., Radley, D. and Hill A.J. (2005) Children's residential weightloss programs can work: A prospective cohort study of short-term outcomes for overweight and obese children. Pediatrics, 116, 73-77. doi:10.1542/peds.2004-0397
[9] Courey, T.J. (2006) Mental health needs of children and adolescents at camp: Are they being assessed and treated appropriately by the camp nurse? Journal of Child and Adolescent Psychiatric Nursing, 19, 215-223. doi:10.1111/j.1744-6171.2006.00074.x

[10] Moons, P., Barrea, C., Suys, B., Ovaert, C., Boshoff, D., Eyskens, B., Vandenrijin, C. and Sluysmans, T. (2006) Improved perceived health status persists three months after a special sports camp for child with congenital heart disease. European Journal of Pediatrics, 165, 767-772. doi:10.1007/s00431-006-0171-7

[11] Wong, W.W., Abrams, S.H., Mikhail, C., Terrazas, N.L., Wilson, T.A., Arceo, D., et al. (2009) An innovative summer camp program improves weight and self-esteem in obese children. Journal of Pediatric Gastroenterology and Nutrition, 49, 493-497. doi:10.1097/MPG.0b013e31819b5da2

[12] Gaslin, R.N. and Snoddy, J. (2009) Imporving quality of life for campers with severe food allergy. http://www.acacamps.org/campmag/issues/0907/severe-f ood-allergy

[13] Holsey, C.N. and Cummings, L. (2008) Evaluating a residential asthma camp program and ways to increase physical activity. Pediatric Nursing, 34, 459-461, 492.

[14] Shelton, K., Duerden, M.D. and Witt, P.A. (2010) Therapeutic camps as respite care providers: Benefits for families of children with disabilities. Camping Magzine, 8, 10.

[15] Briery, B.G. (2004) Family camping: Building a community at warp speed the special case of family camping. Camping Magazine, July/August.

[16] Taylor S., Covey J.F. and Covey C.D. (2006) Family camps: Strengthening family relationships at camp and at home. Camping Magazine, July/August.

[17] Zotti, M.E., Graham, J., Whitt, A.L., Anand, S. and Replogle, W.H. (2006) Evaluation of a multistate faith-based program for children affected by natural disaster. Public Health Nursing, 23, 400-409. doi:10.1111/j.1525-1446.2006.00579.x

[18] Schachter, S.R. (2007) Bereavement summer camp for children and teens: A reflection of nine years. Palliat Support Care, 5, 315-323. doi:10.1017/S1478951507000478

[19] Wallace, S. (2006) Rites of passage: Camp pays off in youth development, happiness, health, and safety. Camping Magazine, May/June.

[20] Simons, L.E., Blount, R.L., Campbell, R., Hubbard, A., Goodwin, B., Devine, K. and Benoit, M. (2007) Decreases in anxiety associated with participation in a camp for children with cardiac defects. Cardiology in the Young, 17, 631-637. doi:10.1017/S1047951107001485

[21] Agate, S.T. and Covey, C.D. (2007) Family camps: An overview of benefits and issues of camps and programs for families. Child and Adolescent Psychiatric Clinics of North America, 16, 921-937. doi:10.1016/j.chc.2007.05.007

[22] Gibbs, A., Moor, S., Frampton, C. and Watkins, W. (2008) Impact of psychosocial interventions on children with disruptive and emotional disorders treated in a health camp. Australian and New Zealand Journal of Psychiatry, 42, 
789-799. doi:10.1080/00048670802277248

[23] Burch, W.R. (2009) The social circles of leisure: Competing explanations. Journal of Leisure Research, 41, 313-335.

[24] Cupers, K. (2008) Governing through nature: Camps and youth movements in interwar Germany and the United States. Cultural Geographies, 15,173-205. doi: $10.1177 / 1474474007087498$

[25] Kiernan, G., Guerin, S. and Maclachlan, M. (2005) Children's voices: Qualitative data from the "Barretstown studies". International Journal of Nursing Studies, 42, 733741. doi:10.1016/j.ijnurstu.2003.05.003

[26] Turton, S.M. (2005) Managing environmental impacts of recreation and tourism in rainforests of the wet tropics of Queensland World Heritage area. Geographical Research, 43, 140-151. doi:10.1111/j.1745-5871.2005.00309.x

[27] Garst, B.A., Williams, D.R. and Roggenbuck, J.W. (2010) Exploring early twenty-first century developed forest camping experiences and meanings. Leisure Sciences, 32, 9097. doi:10.1080/01490400903430905

[28] Corbin, C.B. and Pangrazi, R.P. (2001) Toward a uniform definition of wellness: A commentary. Research Digest, $\mathbf{3}$, $1-8$.

[29] Ren, H., Xing, W.H. and Fu, F. (2007) The concept of wellness from the perspective of Chinese culture. Journal of Exercise Science \& Fitness, 5, 95-101.

[30] Kang, K., Sung and Kim, C.Y. (2010) High risk groups in health behavior defined by clustering of smoking, alcohol, and exercise habits. Journal of Preventive Medicine and Public Health, 5, 39-47.

[31] Kosti, R.L., Pagagiotakos, D.B., Mariolis, A., et al. (2009) The diet-lifestyle index evaluating the quality of eating and lifestyle behaviors in relation to the prevalence of overweight/obesity in adolescents. International Journal of Food Science \& Nutrition supplement, 13, 34-48. doi:10.1080/09637480802534525

[32] Nowak, M., Rynkiewicz, T., Radzinska, M., et al. (2009) Conditions of a sporting lifestyle in 20-75-year-old polish women. International Scientific Journal of Kinesiology, 3, 19-26.

[33] Engstrom, L.M. (2008) Who is physical active? Cultural capacity and sports participation from adolescence to middle age-A 38-year follow-up study. Physical Education \& Sport Pedagogy, 13, 319-334. doi:10.1080/17408980802400510

[34] Khaw, K.T., Wareham, N., Bingham, S., et al. (2008) Combined impact of health behaviors and mortality in men and women: The EPIC-norfolk prospective population study. PLoS Medicine, 5, 39-47. doi:10.1371/journal.pmed.0050012

[35] Mitchell, J.A., Bornstein, D.B., Siu, X.M., et al. (2010) The impact of combined health factors on cardiovascular disease mortality. American Heart Journal, 160, 102-108. doi:10.1016/j.ahj.2010.05.001

[36] Ma, J., Betts, N.M. and Hampl, J.S. (2000) Clustering of lifestyle behaviors: The relationship between cigarette smoking, alcohol consumption, and dietary intake. American Journal of Health Promotion, 15, 107-117. doi:10.4278/0890-1171-15.2.107

[37] Fu, F.H. and Fung, L. (2004) The cardiovascular health of residents in selected metropolitan cities in China. Preventive Medicine, 38, 458-467. doi:10.1016/i.ypmed.2003.11.022

[38] Chou, K.L.(2008) The prevalence and clustering of four major lifestyle risk factors in Hong Kong Chinese older adults. Journal of Aging and Health, 20, 788-803. doi:10.1177/0898264308321082

[39] Ko, G.T., Chan, J.C., Chan, A.W., et al. (2007) Association between sleeping hours, working hours and obesity in Hong Kong Chinese: The better health for better Hong Kong's health promotion campaign. International Journal of Obesity (London), 31, 254-260. doi:10.1038/sj.ijo.0803389

[40] Center for Health Protection, Department of Health, HKSAR (2008) Statistics on behavioral risk factors. http://www.dh.gov.hk/english/statistics/statistics_hs.html 


\section{Appendix A}

\section{Questionnaire on Lifestyle Survey}

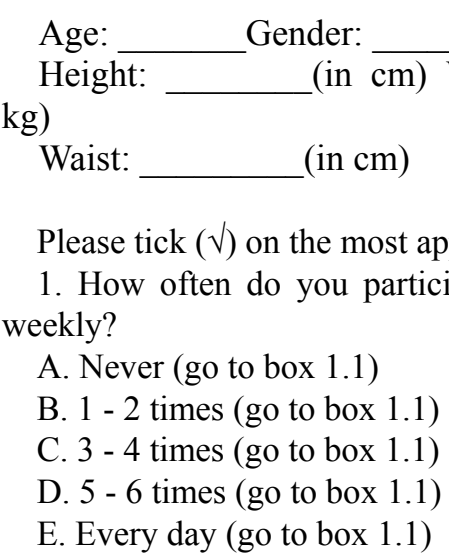

Box 1. (Please tick $(\sqrt{ })$ on the most appropriate answer).

\begin{tabular}{cl}
\hline 1 & Never thought of doing exercise at all \\
\hline 2 & $\begin{array}{l}\text { Have thought of it and may begin regular exercise in the next } \\
6 \text { months }\end{array}$ \\
3 & $\begin{array}{l}\text { Have made plans to exercise regularly in the very near future } \\
\text { (maybe next month) }\end{array}$ \\
\hline
\end{tabular}

2. How about do you eat snack?

A. Never (go to box 2.1)

B. Less than once/week

C. 2 - 3 times/week (go to box 2.1)

2.1)

D. Regularly-More than 3 times per week (go to box

E. Every Day (go to box 2.1)

Box 2. (Please tick $(\sqrt{ })$ on the most appropriate answer).

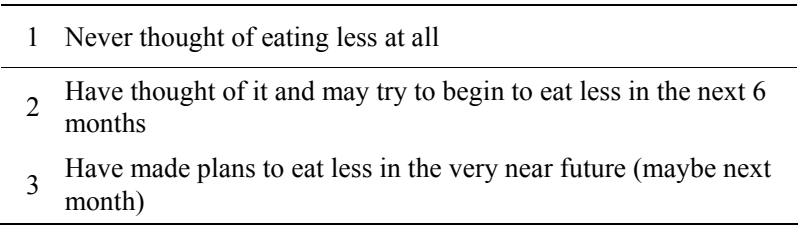

3. Do you eat breakfast?

A. Never (go to box 3.1)

B. Less than once/week (go to box 3.1)

C. 2 - 3 times/week (go to box 3.1)

D. Regularly-More than 3 times per week

E. Every Day

Box 3. (Please tick $(\sqrt{ })$ on the most appropriate answer).

\begin{tabular}{ll}
\hline 1 & Never thought of eating breakfast regularly at all \\
\hline 2 & $\begin{array}{l}\text { Have thought of it and may begin eating breakfast regularly in } \\
\text { the next } 6 \text { months }\end{array}$ \\
3 & $\begin{array}{l}\text { Have made plans to eat breakfast regularly in the very near future } \\
\text { (maybe next month) }\end{array}$ \\
\hline
\end{tabular}

4. Do you eat 3 meals at regular times each day?

A. Never (go to box 4.1)

B. Less than once/week (go to box 4.1)

C. 2 - 3 times/week (go to box 4.1)

D. Regularly-More than 3 times per week

E. Every Day

Box 4. (Please tick $(\sqrt{ })$ on the most appropriate answer).

1 Never thought of eating 3 meals regularly each day

Have thought of it and may begin eating 3 meals/day

regularly in the next 6 months

Have made plans to eat 3 meals/day regularly the very near future (maybe next month)

5. Do you eat vegetables or fruit?

A. Never (go to box 5.1)

B. Less than once/week (go to box 5.1)

C. 2 - 3 times/week (go to box 5.1)

D. Regularly-More than 3 times per week (go to box

5.1)

E. Every Day

Box 5. (Please tick $(\sqrt{ })$ on the most appropriate answer).

1 Never thought of eating vegetables or fruit at all

2 Have thought of it and may try to eat more vegetables or fruit in

2 the next 6 months

3 Have made plans to eat more vegetables or fruit in the very near 3 future (maybe next month)

6. How many hours do you normally sleep a day?

A. 4 hours or less per day (go to box 6.1)

B. 4 - 5 hours per day (go to box 6.1)

C. 6 - 7 hours per day (go to box 6.1)

D. 8 - 9 hours per day (go to box 6.1)

E. 10 hours or more per day (go to box 6.1)

Box 6. (Please tick $(\sqrt{ })$ on the most appropriate answer).

1 Never thought of sleeping more at all

2 Have thought of it and may try to sleep more in the next 6 months Have made plans to sleep more in the very near future (maybe next
month)

7. Do you drink (alcohol)?

A. Never (go to box 7.1)

B. Less than once/week

C. 2 - 3 times/week (go to box 7.1)

D. Regularly-More than 3 times per week (go to box

7.1)

E. Every Day (go to box 7.1) 
Box 7. (Please tick $(\sqrt{ })$ on the most appropriate answer).

1 Never thought of drinking less at all

2 Have thought of it and may begin to drink less in the next 6 months

3 Have made plans to drink less in the very near future (maybe next month)

8. Do you smoke (cigarette)?

A. Never (go to box 8.1)

B. Less than once/week

C. 2 - 3 times/week (go to box 8.1)

D. Regularly-More than 3 times per week (go to box

8.1)

E. Every Day (go to box 8.1)

Box 8. (Please tick $(\sqrt{ })$ on the most appropriate answer).

1 Never thought of smoking less at all

2 Have thought of it and may begin to smoke less in the next 6

months Have made plans to smoke less in the very near future (maybe next
month)
9. Have you gone to camping before?

A. Never (go to box 9.1)

B. Less than once/year (go to box 9.1)

C. 2 - 3 times/year (go to box 9.1)

D. Regularly-More than 3 times per year (go to box 9.1)

E. Every month (go to box 9.1)

Box 9. (Please tick $(\sqrt{ })$ on the most appropriate answer).

\begin{tabular}{cc}
\hline 1 & Never thought of going to camping at all \\
\hline 2 & Have thought of it and may begin to go camping in the next 6 \\
months
\end{tabular}

